Eenter for Modern Oriental Studies

\title{
Changing Identities
}

\section{The transformation of Asian and African societies under colonialism}

Papers of a symposium held at the Centre for Modern Oriental Studies, Berlin, 21-22 October 1993

Ed. by Joachim Heidrich

\section{Studien 1}

ЏVerlag Das Arabische Buch 
Die Deutsche Bibliothek - CIP-Einheitsaufnahme

Heidrich, Joachim (Hg):

Changing Identities. The Transformation of Asian and African Societies under colonialism / Joachim Heidrich. - Berlin: Verl. Das Arabische Buch, 1994

(Studien / Forschungsschwerpunkt Moderner Orient,

Förderungsgesellschaft Wissenschaftliche Neuvorhaben mbH; $\mathrm{Nr}$. 1) ISBN 3-86093-062-1

NE: Förderungsgesellschaft Wissenschaftliche Neuvorhaben <Mūnchen > / Forschungsschwerpunkt Moderner Orient: Studien

Forschungsschwerpunkt Moderner Orient

Förderungsgesellschaft Wissenschaftliche Neuvorhaben $\mathrm{mbH}$

Kommissarischer Leiter:

Prof. Dr. Peter Heine

Prenzlauer Promenade 149-152

13189 Berlin

Tel. $030 / 4797319$

ISBN 3-86093-062-1

STUDIEN

Bestellungen:

Das Arabische Buch

Horstweg 2

14059 Berlin

Tel. $030 / 3228523$

Redaktion und Satz: Margret Liepach, Helga Reher

Druck: Druckerei Weinert, Berlin

Printed in Germany 1994 